\title{
Radiotherapy in Bone Metastases
}

\author{
Selnur ÖZKURT, (1) Esra KAYTAN SAĞLAM
}

Department of Radiation Oncology, Istanbul University, Istanbul Faculty of Medicine, Istanbul-Turkey

\section{Introduction}

Advanced-stage metastases are common in bone. Bone metastases may cause pain, movement limitation, pathological fracture, neurological deficits due to spinal compression of the medulla, and malignant hypercalcemia; however, they may cause deterioration in the quality of life of patients.[1] Lung, thyroid, and renal cell cancers, malignant melanoma, and multiple myeloma often metastasize to the bones.[2] Bone metastasis is observed in $70-90 \%$ of patients who die due to breast and prostate cancer.[3] Bone metastases are common in the vertebral column, pelvis, humerus, and femur, while joint metastases such as knee and elbow are typical for lung cancer.[4]

Owing to the development of new systemic treatments, targeted agents, and immunotherapies in patients with cancer, survival expectancy in metastatic disease has increased; therefore, pain palliation has become more important. Radiotherapy (RT) is the gold standard in relieving pain due to bone metastases. Although there are many prospective and retrospective randomized controlled studies, there is no consensus on the most effective RT dose and schedule for pain palliation due to bone metastasis. [5]

A total of 1016 patients with painful bone metastases were included in the RTOG 7402 study, and effects of five different dosing schedules (40.5 Gray [Gy]/15 fractions [fr], $30 \mathrm{~Gy} / 10 \mathrm{fr}, 25 \mathrm{~Gy} / 5 \mathrm{fr}, 20 \mathrm{~Gy} / 5 \mathrm{fr}, 15$ $\mathrm{Gy} / 5 \mathrm{fr}$ ) on pain palliation and analgesic use were evaluated. Minimal pain palliation was achieved in $89 \%$ of the patients, partial pain in $83 \%$, and complete pain palliation in $54 \%$ of patients, and no difference was observed between the arms. Complete pain palliation was obtained 4 weeks after the initiation of treatment in patients, and this period was similar between the arms. In pain palliation, it was observed that the response

Accessible online at: www.onkder.org

OPEN ACCESS This work is licensed under a Creative Commons Attribution-NonCommercial 4.0 International License. was low, particularly in patients with a high baseline pain score and who could not complete the treatment as planned, while pain palliation was better with treatment in those with breast and prostate cancer.[6]

In the comparative study of the Dutch bone metastasis group, 1157 patients received $8 \mathrm{Gyx} 1 \mathrm{fr}$ and 4 Gyx6 fr RT. Metastasis was observed in 30\% vertebra, $36 \%$ pelvic bones, $10 \%$ femur, and pain palliation was achieved in $71 \%$ of all patients, and complete response was observed in $35 \%$ of the patients. The median response time was about 3 weeks in both arms. While the response time (20-24 months) and the rate of returning pain to pre-treatment level (52-46\%) were similar between the arms, the need for repeat RT was found to be less in the $6 \mathrm{fr}$ applied arm (7-25\%).[7]

In the RTOG 9714 study, 30 Gy/10 fr treatment, which is frequently used in metastases, was compared with $8 \mathrm{~Gy}$ in a single fraction. While, on the complaint of pain, the response rate was $66 \%$ in both arms, it was reported that complete response was better (50-15\%) in the $10 \mathrm{fr}$ treatment arm and less required for RT (9$18 \%)$. Acute grade $2-4$ toxicity, mostly related to the gastrointestinal tract, was more common in the multifraction arm (7-17\%).[8]

Chow et al. reported pain palliation rate $(60 \%)$, complete response rates (24\%), and fracture risk (3\%) similarly in both arms in a meta-analysis of 25 randomized studies involving 5617 patients with bone metastases treated using single and multiple fractionation schemes. The need for re-irradiation was higher in the single-dose RT arm (8-20\%, p<0.00001). $[9,10]$ Bayard et al. and Howell et al.[11,12] found that pain palliation rates and analgesic requirements decreased by $70-80 \%$ similarly in both RT schemes in $8 \mathrm{~Gy} / 1 \mathrm{fr}$ and $30 \mathrm{~Gy} / 10$ fr schemes; however, the need for re-irradiation increased more in single fr schemes.
Dr. Esra KAYTAN SAĞLAM

İstanbul Üniversitesi,

İstanbul Tıp Fakültesi,

Radyasyon Onkolojisi Anabilim Dalı, İstanbul-Turkey

E-mail: esrasaglam@gmail.com 
In the American Society of Radiation Oncology (ASTRO) guidelines, the re-irradiation requirement has been defined as persistent or recurring pain states at the earliest 1 month after the first irradiation and it can be applied by focusing on critical organ dose limitations.[13] In international multi-center comparative studies, the pain response with re-irradiation is $45 \%$ in single fr schemes and $51 \%$ in multiple fr schemes in uncomplicated bone metastases (no pathological fractures or medulla spinalis compression), and the response obtained is independent of the applied dose scheme and previous RT response. $[8,11]$ It has been reported that the 8 Gyx 1 fr scheme can be applied safely for pain palliation in patients with a limited lifespan and difficult access to the hospital when re-treatment is required.[13]

$\mathrm{RT}$ is a recommended approach after stabilization and /or decompression surgeries in patients with complicated bone metastases with pathological fractures and/or spinal cord compression. [13] Pathological fracture risk in the long bone located metastases is evaluated using Mirels scoring system and RT is recommended after prophylactic internal fixation surgery in patients with a score $\geq$ of 8.[14] In vertebral metastases, it is recommended to make a treatment decision by using the Spinal Instability Scoring System by examining the necessity of decompression/vertebroplasty surgery. [15] Those with a score of 7-12 are classified as potentially unstable lesions, and those with a score of 13-18 as unstable lesions, and all lesions with a score $>7$ are recommended to be evaluated surgically. The Bilsky scoring system, which evaluates epidural spinal cord compression, is also important in palliative treatment planning in patients with spinal metastases.[16] In a randomized controlled study by Patchell et al.[17] with 100 patients who were paraplegic for less than 48 $\mathrm{h}$ and life expectancy $>3$ months, that patient mobility (84-57\%, $\mathrm{p}=0.001)$, time to patient mobilization (13122 days, $\mathrm{p}=0.003)$ and median survival (100-126 days, $\mathrm{p}=0.03$ ) were statistically significantly better than the same dose schema RT after decompression surgery versus only $30 \mathrm{~Gy} / 10 \mathrm{fr}$ RT arm.

One of the important toxicities of RT applied in bone metastases is pain exacerbation in the RT applied area. Pain exacerbation is defined as a two-point increase in pain score, which lasts for about 10 days or $25 \%$ more analgesic requirement without an increase in pain. It was observed earlier that the incidence of pain exacerbation is $2-44 \%$ in the patients those underwent conventional palliative $\mathrm{RT}$, and this rate reaches $10-68 \%$ in those undergoing spinal stereotactic ablative body radiotherapy (SBRT).[18] When Yousef et al.[19] compared intravenous administration of $5 \mathrm{mg} /$ $\mathrm{kg}$ methylprednisolone and placebo before treatment with $30 \mathrm{~Gy} / 10$ fr RT in 120 patients with painful vertebral metastasis, they showed that pain exacerbation in the steroid infusion arm was significantly low (7$20 \%, \mathrm{p}<0.05)$ and this period were significantly short $(1.25-3.75, \mathrm{p}<0.05)$ in those with pain exacerbation. In a placebo-controlled double-blind, randomized study, Chow et al.[20] found that $8 \mathrm{mg}$ dexamethasone administered orally $1 \mathrm{~h}$ before and 4 days after RT reduced pain exacerbation by $9 \%$ in patients who received $8 \mathrm{~Gy} / 1$ fr RT (26-35\%, p=0.05) and that it increased the appetite on the $10^{\text {th }}$ day by reducing nausea. However, there are still uncertainties in terms of the most effective steroid dose and duration of use, and drugs that can be used instead of steroids.

Image-guided radiotherapy, intensity-modulated radiotherapy, and SBRT coming with technological advances, have also been used in bone and spinal metastases, and promising results have been reported. With SBRT, a higher dose can be given to the target tissue, while the surrounding critical tissues are protected with sharper borders. Knowing that similar pain response is obtained in palliative RT schemes used in daily practice and due to the need for re-irradiation seen in $8 \mathrm{~Gy} / 1 \mathrm{fr}$ schemes, it is aimed to higher pain palliation and to reduce re-treatment requirement with SBRT applications where the biological equivalent dose is high. In particular, with the concept of oligometastatic disease defined by Hellman and Weichselbaum in 1995, local control rates have gained importance for symptomatic palliation. The Stereotactic Ablative Radiotherapy for the Comprehensive Treatment of Oligometastases (SABR-COMET) study showed the contribution of SBRT to overall survival and progression-free survival in limited metastatic disease.[21] However, in radiation-resistant tumor histologies (malignant melanoma, sarcoma, kidney cell tumor) the observation of tumor response that could not be achieved using conventional treatments also made SBRT applications preferable for this group of patients.[22]

In the RTOG 0631 study comparing the effect of SBRT (16 Gy or 18 Gy in a single fraction) and conventional $8 \mathrm{~Gy} / 1 \mathrm{fr}$ RT on pain control in spinal metastases, pain palliation was similar in both arms at the third month after treatment (40.4-57.9\%, $\mathrm{p}=0.99)$. [23] In the Canadian Cancer Trials group-SC24 study conducted by the Canadian Cancer Working Group, 24 Gy/2 fr SBRT was compared with $20 \mathrm{~Gy} / 5 \mathrm{fr}$ in 229 patients with painful spinal metastases, and at the third month after treatment, complete pain control was $14 \%$ in the 
conventional arm and $36 \%$ in the SBRT arm $(\mathrm{p}<0.001)$; it was found to be $16-33 \%(\mathrm{p}=0.004)$ at the sixth month. Vertebral compression fracture after RT was $17 \%$ in the $20 \mathrm{~Gy} / 5 \mathrm{fr}$ arm, $11 \%$ in the SBRT arm, and progressionfree survival was $86-92 \%$ at the third month in the RT area $(\mathrm{p}=0.4)$, and it was detected that these ratios were $69-75 \%(\mathrm{p}=0.42)$ in the sixth month.[24]

Patient selection is important for SBRT applications in spinal bone metastases. The Prognostic Index for Spinal Metastases, which includes parameters such as the patient's age, performance status, functional capacity, time from diagnosis to metastasis, and the number of metastases may be considered in patient selection (Fig. 1).[25]

In the evidence-based guidelines of ASTRO, it is stated that SBRT can be used in oligometastatic cases with long life expectancy, good performance, in patients who have difficulty in transportation to the hospital or need re-irradiation; however, it is more appropriate to perform this application within the scope of the study.[13]

In particular, myelopathy and vertebral compression fractures are among the feared toxicities in highdose stereotactic treatments. The risk of SBRT-related vertebral compression fracture is particularly high in lytic lesions and single fraction high-dose ( $\geq 24$ Gy) SBRT applications. Rose et al.[26] observed the fracture risk to be $39 \%$ in 18-24 Gyx 1 fr applications and found that this risk could increase in lytic lesions covering $>40 \%$ of the vertebral corpus in T10 and lower vertebrae as a risk factor. The dose and risk ratios defined by Sahgal et al.[27] for RT-induced myelopathy are spinal cord $\mathrm{D}_{\max }$ is $1 \%$ at $17 \mathrm{~Gy} / 2 \mathrm{fr}, 2 \%$ at $20.3 \mathrm{~Gy} / 3$ fr, $3 \%$ at $23 \mathrm{~Gy} / 4 \mathrm{fr}, 5 \%$ at $25.3 \mathrm{~Gy} / 5 \mathrm{fr}$.

In painful bone metastases, the use of radiopharmocytic (Samarium-153, Strontium-89, Radium-223) agents and bisphosphonates (ibandronate, denosumab) for palliation is increasingly common.

\section{Conclusion}

Bone metastases are frequently encountered in patients with advanced-stage cancer. In the light of published prospective and retrospective studies, the most appropriate treatment approach should be determined based on patient and tumor characteristics, clinical possibilities, and experiences. There are several favorable similar efficacy RT doses and schedules available. Survival advantages obtained with SBRT should not be ignored, particularly in oligometastatic disease.
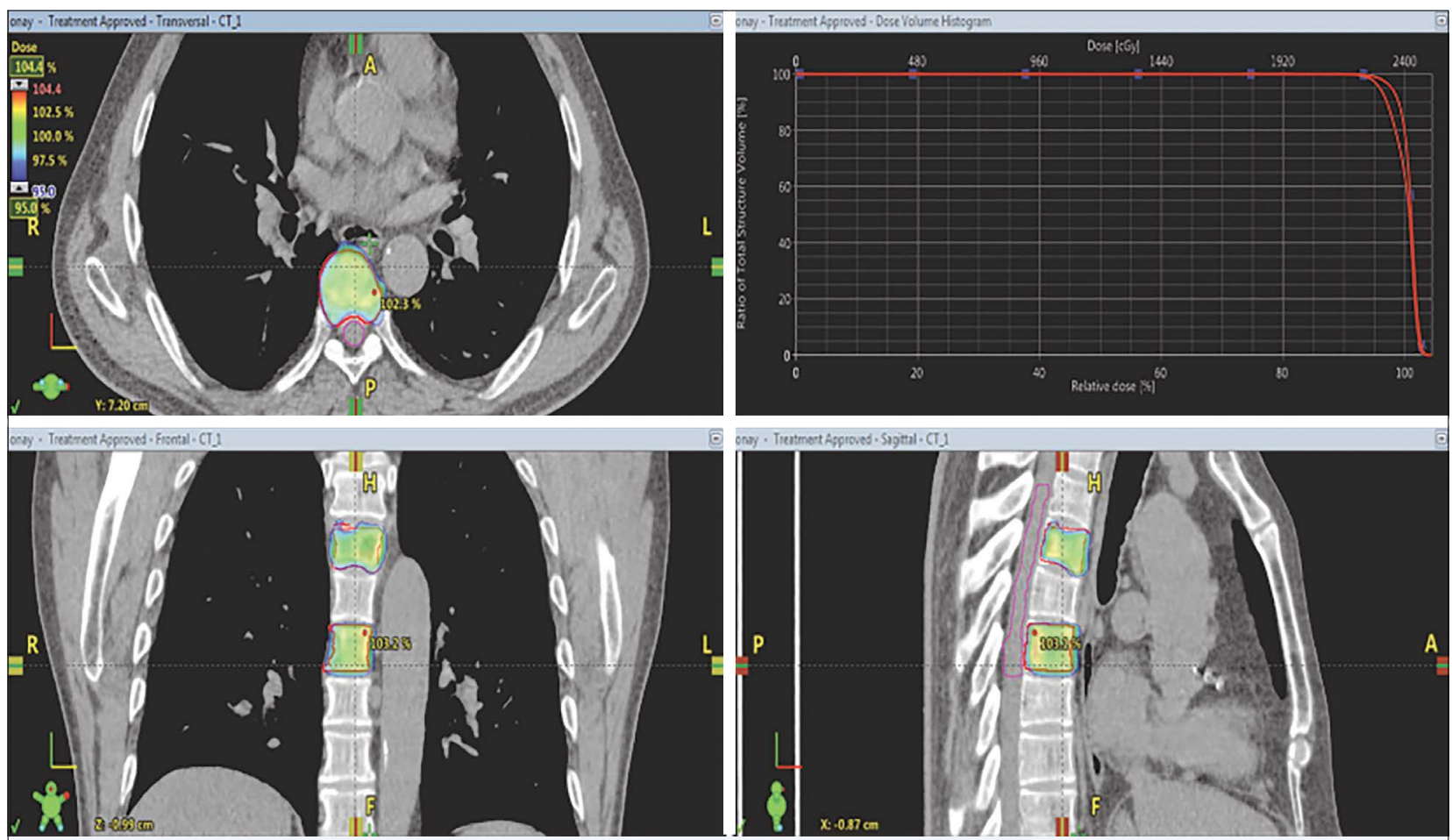

Fig. 1. Vertebra stereotactic RT. RT: Radiotherapy. 
Those coming with the developing technology, ongoing prospective studies, developments in the pharmaceutical industry, and new treatment options should be followed, and the treatment decision should be determined in multidisciplinary meetings.

\section{References}

1. Berenson JR, Rosen LS, Howell A, Porter L, Coleman RE, Morley W, et al. Zoledronic acid reduces skeletalrelated events in patients with osteolytic metastases. Cancer 2001;91(7):1191-200.

2. Macedo F, Ladeira K, Pinho F, Saraiva N, Bonito N, Pinto L, et al. Bone metastases: An overview. Oncol Rev 2017;11(1):321.

3. Jemal A, Bray F, Center MM, Ferlay J, Ward E, Forman D. Global cancer statistics. CA Cancer J Clin 2011;61(2):69-90.

4. Healey JH, Turnbull AD, Miedema B, Lane JM. Acrometastases. A study of twenty-nine patients with osseous involvement of the hands and feet. J Bone Joint Surg Am 1986;68(5):743-6.

5. Nguyen QN, Chun SG, Chow E, Komaki R, Liao Z, Zacharia R, et al. Single-fraction stereotactic vs conventional multifraction radiotherapy for pain relief in patients with predominantly nonspine bone metastases. A randomized phase 2 trial. JAMA Oncol 2019;5(6):872-8.

6. Tong D, Gillick L, Hendrickson FR. The palliation of symptomatic osseous metastases final results of the study by the Radiation Therapy Oncology Group. Cancer 1982;50(5):893-9.

7. Steenland E, Leer JW, van Houwelingen H, Post WJ, van den Hout WB, Kievit J, et al. The effect of single fraction compared to multipl fractions on painful bone metastases: A global analysis of the Dutch Bone Metastases Study. Radiother Oncol 1999;52(2):101-9.

8. Hartsell WF, Scott CB, Bruner DW, Scarantino $\mathrm{CW}$, Ivker RA, Roach $\mathrm{M}$, et al. Randomized trial of short versus long course radiotherapy for palliation of painful bone metastases. J Natl Cancer Inst 2005;97(11):798-804.

9. Chow E, Harris K, Fan G, Tsao M, Sze WM. Palliative radiotherapy trials for bone metastases: A systematic review. J Clin Oncol 2007;25(11):1423-36.

10. Chow E, Zeng L, Salvo N, Dennis K, Tsao M, Lutz S. Update on systematic review of palliative radiotherapy trials for bone metastases. Clin Oncol 2012;24(2):11224.

11. Howell DD, James JL, Hartsell WF, Suntharalingam M, Machtay M, Suh JH, et al. Single fraction radiotherapy versus multifraction radiotherapy for palliation of painful vertebral bone metastases-equivalent efficacy, less toxicity, more convenient: A subset analysis of Radiation Therapy Oncology Group trial 9714. Cancer 2013;119(4):888-96.

12. Bayard LG, Buzon MDCS, Pain EA, Baron LI. Radiation therapy for the management of painful bone metastases: Results from a randomized trial. Rep Pract Oncol Radiother 2014;19(6):405-11.

13. Lutz S, Balboni T, Jones J, Lo S, Petit J, Rich SE, et al. Palliative radiation therapy for bone metastases: Update of an ASTRO Evidence-Based Guideline. Pract Oncol Radiother 2017;7:4-12.

14. Mirels H. Metastatic disease in long bones. A proposed scoring system for diagnosing impending pathologic fractures. Clin Ortop Relat Res 1989;(249):256-64.

15. Fisher GG, Schouten R, Versteeg AL, Boriani S, Varga PP, Rhines LD, et al. Reliability of the Spinal Instability Neoplastic Score (SINS) among radiation oncologists: An assessment of instability secondary to spinal metastases. Radiat Oncol. 2014;9:69.

16. Bilsky MH, Laufer I, Fourney DR, Groff M, Schmidt $\mathrm{MH}$, Varga PP, et al. Reliability analysis of the epidural spinal cord compression scale. J Neurosurg Spine 2010;13(3):324-8.

17. Patchell RA, Tibbs PA, Regine WF, Payne R, Saris S, Kryscio RJ, et al. Direct decompressive surgical resection in the treatment of spinal cord compression caused by metastatic cancer: A randomised trial. Lancet 2005;366(9486):643-8.

18. McDonald R, Chow E, Rowbottom L, DeAngelis C, Soliman $\mathrm{H}$. Incidence of pain flare in radiation treatment of bone metastases: A literature review. J Bone Oncol 2014;3(3-4):84-9.

19. Yousef AAAM, El-Mashad NM. Pre-emptive value of methylprednisolone intravenous infusion in patients with vertebral metastases. A double-blind randomized trial. J Pain Symptom Manage 2014;48(5):762-9.

20. Chow E, Meyer RM, Ding K, Nabid A, Chabot P, Wong $\mathrm{P}$, et al. Dexamethasone in the prophylaxis of radiation-induced pain flare after palliative radiotherapy for bone metastases: A double-blind, randomized placebo-controlled, phase 3 trial. Lancet Oncol 2015;16(15):1463-72.

21. Palma DA, Olson R, Harrow S, Gaede S, Louie AV, Haasbeek C, et al. Stereotactic ablative radiotherapy versus standard of care palliative treatment in patients with oligometastatic cancers (SABR-COMET): A randomised, phase 2, open-label trial. Lancet 2019;393(10185):2051-58.

22. Nguyen QN, Shiu AS, Rhines LD, Wang H, Allen PK, Wang XS, et al. Management of spinal metastases from renal cell carcinoma using stereotactic body radiotherapy. Int J Radiat Oncol Biol Phys 2010;76(4):1185-92. 
23. Ryu S, Deshmukh S, Timmerman RD, Movsas V, Gerszten PC, Yin FF, et al. Radiosurgery compared to external beam radiotherapy for localized spine metastases: Phase 3 results of NRG/RTOG 0631. Int J Radiat Oncol Biol Phys 2019;105(1):2-3.

24. Sahgal A, Myrehaug SD, Siva S, Masucci L, Foote MC, Brundage M, et al. CCTG SC.24./.TROG 17.06: A randomised phase II/III study comparing 24 Gy in 2 stereotactic body radiotherapy (SBRT) fractions versus $20 \mathrm{~Gy}$ in 5 conventional palliative radiotherapy (CRT) fractions for patients with painful spinal metastases. Int $\mathrm{J}$ Radiat Oncol Biol Phys 2020;108(5):1397-8.
25. Jensen G, Tang C, Hess KR, Bishop AJ, Pan HY, Li J, et al. Internal validation of the prognostic index for spine metastasis (PRISM) for stratifying survival in patients treated with spinal stereotactic radiosurgery. J Radiosurg SBRT 2017;5(1):25-34.

26. Rose PS, Laufer I, Boland PJ, Hanover A, Bilsky MH, Yamada $j$, et al. Risk of fracture after single fraction image-guided intensity modulated radiation therapy to spinal metastases. J Clin Oncol 2009;27(30):5075-9.

27. Sahgal A, Chang JH, Ma L, Marks LB, Milano MT, Medin P, et al. Spinal cord dose tolerance to stereotactic body radiation therapy. Int J Radiat Oncol Biol Phys 2021;110(1):124-36. 